\title{
Editorial
}

\section{Systematically sceptical}

One can no longer rely on the presumption that scientists comply with the Mertonian value of disinterest and assume that they always tell the truth when spreading the results of their research projects. This can be rightly considered as the gist of the four-page report submitted to the board of the American journal Science by the committee chaired by the chemist John Brauman, from the Stanford University, and comprising three members from the Senior Editorial Board of the same journal, two eminent biologists specialised in stem cell research and a top editor from the other major general press medium of the Republic of Science, the British journal Nature.

This committee had been appointed by the Science board itself earlier last summer, six months after the outbreak of the Hwang affaire, one of the major frauds in the history of science communication. Precisely one year ago it was discovered that the South-Korean biologist Woo Suk Hwang had substantially manipulated the data for two articles published in Science in 2004 and 2005. Two very important articles announcing, among other things, that a line of human stem cells had been obtained by cloning an embryo in its earliest development phases.

At least two issues have emerged from this episode. How could a biologist of such great standing, one of the major experts on cloning in the whole world, possibly attempt such a sensational fraud? How could the rigorous peer-review system of a journal like Science possibly prove to be unable to detect such a fraud and stop it at the outset?

The first question concerns essentially scientists themselves, psychologists and sociologists of science. The second question relates to anyone involved in science communication. JCOM has raised it, as our readers may remember, proposing a reflection on the limitations of peer review in the post-academic era of science. The Science board has has also addressed this matter, appointing the Brauman committee.

This committee has put forward a proposal to reform the traditional peer-review procedure on the basis of four pillars: a careful evaluation of the risk associated with some articles having a potentially dramatic impact; a clearer definition of the responsibilities to be assumed by the authors of the articles; a request for further data to help a more in-depth verification of the correctness of research methodology; the definition of common rules to be accepted at least by high-profile journals, starting from Science and Nature.

Behind this proposal by the Brauman committee, welcomed by the Science editor, lies a newlyacquired awareness that something has changed in the way scientists work (and communicate). From the outset one of the fundamental values of the scientific community was the lack of vested interests (at an economic, political and personal level). Clearly, this has not prevented deviant behaviour from some scientists. But any such behaviour within the Republic of Science was indeed perceived as deviant. It has thus been possible to build the entire system of science communication on the principle that scientists tend to tell the truth when communicating the results of their research projects, because they know their lies would be soon discovered and severely punished.

In the post-academic era of science, along with the growth of huge external interests (political and/or economic), the grounds on which this principle lies have become slightly more shaky. Either because lies are not easily unveiled. Or because, on the border between science and society, reticence is hardly punished as severely as in the past.

One should therefore no longer take for granted that, as in the past, scientists are pushed only by noble motives and are naturally inclined to tell the truth.

Should we now think of new rules founded on a set of values differing from the Mertonian one? The Brauman committee says no. If, on the one hand, the lack of vested interests in scientific work has been adversely affected to a certain extent, on the other, the functioning of the system may be still saved within the set of values drawn by Robert Merton. All we need to do is to empower systematic scepticism and make it more pressing.

Pietro Greco 